90

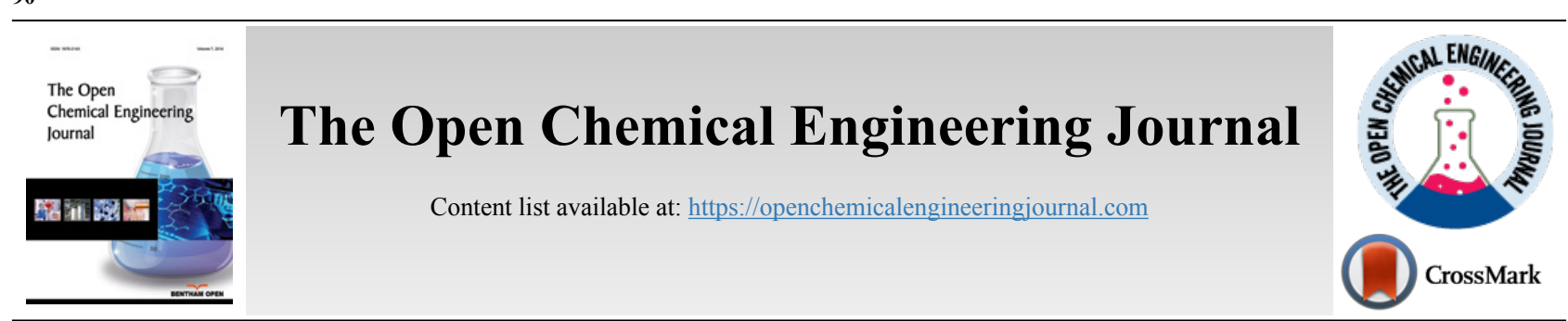

RESEARCH ARTICLE

\title{
Electrochemical Fabrication of Poly (niacin) Modified Graphite Paste Electrode and its Application for the Detection of Riboflavin
}

\author{
J. G. Manjunatha ${ }^{1, *}$, C. Raril ${ }^{1}$, N. Hareesha ${ }^{1}$, M.M. Charithra ${ }^{1}$, P.A. Pushpanjali ${ }^{1}$, Girish Tigari ${ }^{1}$, D.K Ravishankar ${ }^{2}$, S. C. \\ Mallappaji ${ }^{3}$ and Jayarame Gowda ${ }^{4}$ \\ ${ }^{\prime}$ Department of Chemistry, FMKMC College, Madikeri, Mangalore University Constituent College, Karnataka, India \\ ${ }^{2}$ Department of Chemistry, Sri Mahadeshwara Govt. First Grade College (University of Mysore), Chamarajanagar, India \\ ${ }^{3}$ Department of Chemistry, Government First Grade College for Women, (Affiliated to University of Mysore), Mysuru, India \\ ${ }^{4}$ Department of Chemistry, Bharathi College, Bharathi nagar, Mandya, India
}

\begin{abstract}
:
Objective:

A poly niacin $(\mathrm{NN})$ modified graphite paste electrode was prepared through a simple electrochemical polymerization route for the determination of Riboflavin (RF)

Methods:

Electropolymerization technique was used for the preparation of a modified electrode. The electrochemical impedance spectroscopy (EIS) method was used to study the surface behaviors and conductivity of the bare and modified electrodes. Cyclic voltammetry (CV) and linear sweep voltammetry (LSV) were used to study the electrochemical behavior of RF using $0.2 \mathrm{M}$ PBS of $7.5 \mathrm{pH}$.

Results:

Poly niacin modified graphite paste electrode (PNNMGPE) provides more affinity towards RF detection with high sensitivity and selectivity over bare graphite paste electrode. RF calibration curve was obtained by LSV between $5.0 \mu \mathrm{M}$ to $65.0 \mu \mathrm{M}$ with $0.782 \mu \mathrm{M}$ limit of detection (LOD) and $2.7608 \mu \mathrm{M}$ limit of quantification (LOQ), respectively. Selective analysis of RF in the presence of ascorbic acid (AA) and dopamine (DA) was performed at PNNMGPE by the LSV method.

Conclusion:

The developed PNNMGPE was tested for RF analysis in a multivitamin tablet with good results. Furthermore, the developed electrode shows good stability and reproducibility.
\end{abstract}

Keywords: Poly niacin, Graphite paste electrode, Riboflavin, Voltammetry, Electropolymerization technique, Electrochemical impedance spectroscopy (EIS).

\begin{tabular}{l|l|l|l} 
Article History & Received: August 28, 2020 & Revised: December 11, 2020 & Accepted: December 14, 2020
\end{tabular}

\section{INTRODUCTION}

Riboflavin (RF) or vitamin $\mathrm{B}_{2}$ is used as a dietary supplement and it is a water-soluble $\mathrm{B}$ group vitamin, and a a constituent of flavoenzymes [1, 2]. It plays an important role in human biochemistry and metabolism. It is not produced in the human body. It is obtained naturally through a food diet. RF is naturally found in nuts, milk, vegetables and fruits, meat, and

* Address correspondence to this author at the Department of Chemistry FMKMC College, Madikeri, Mangalore University Constituent College, Karnataka, India Tel: +91- 08272228334; E-mail: manju1853@gmail.com eggs. Deficiency of RF in the human body can lead to eye and skin disorders, microcytic hypo-chronic anemia, night blindness (beriberi), pellagra or sometimes even death [3 - 7]. Also, RF overdose can cause oxidative damage to DNA and tissue by UV radiation exposure [7 - 11]. So it is important to develop a simple and sensitive analytical method to determine RF.

Existing methods in analyzing RF include chromatography, UV-spectrophotometry, chemiluminescence, Reversed-Phase-High-performance liquid chromatography, 
spectrofluorimetry, mass spectroscopy, flow injection analysis, Capillary zone electrophoresis, Reversed-Phase Liquid Chromatography, surface plasmon resonance, etc [12 - 23]; these methods need expensive instruments and complicated procedures. Electroanalytical methods are the best alternatives to the above methods, are relatively cheap and easy but provide excellent analytical performance for the detection of bioactive molecules [24 - 32]. There are many electroanalysis reports available in the literature for RF estimation such as highly dispersed multi-walled carbon nanotubes coupled manganese salen nanostructure, $\mathrm{ZnO} /$ Manganese hexacyanoferrate nanocomposite/glassy carbon electrode, manganese (III) tetraphenyl porphyrin modified carbon paste electrode, poly (3methyl thiophene) modified glassy carbon electrode, poly deoxy adenylic acid/reduced graphene oxide, DNAfunctionalized biosensor and polymer modified carbon paste electrode and some other. Different modified electrodes using amino acids, dyes, nucleotides, neurotransmitters, phenolic compounds, metal nanoparticles, metal complexes, clay, ionic liquids, surfactants, metal oxides, enzymes and DNA modified sensors etc., with different functional groups are widely reported for determination of electroactive species due to their stability, electrocatalytic performance, biocompatibility, antifouling properties, and high applicability [33 - 44]. Modified electrode controls over potential and improves the sensitivity of sensors. Carbon materials such as graphite, carbon nanotube, graphene, pencil graphite, glassy carbon, activated carbon, and biomass carbon are the best choices for the fabrication of sensors and supercapacitors due to their extensive potential domains, chemical inertness, low ohmic resistance, robustness, mechanical stability, excellent material characteristics, provides lower detection limits with reproducible responses, high surface area, good thermal and electrical conductivity, good anti-causticity, high stability, low cost and commercial-scale availability [45 - 57]. The present effort describes RF quantification and detection at PNNMGPE using the voltammetry technique.

\section{MATERIALS AND METHODS}

\subsection{Instrumentation}

The electrochemical measurements were achieved by CHI-6038E electrochemical workstation (from USA), which consists of a tri electrode arrangement in an electrochemical chamber with a saturated calomel electrode (reference electrode), platinum wire (counter electrode), bare carbon paste electrode (BGPE) and PNNMGPE (working electrode).

\subsection{Chemicals and Solutions}

RF, NN, AA and DA were bought from Molychem, India. Potassium chloride, silicone oil, and graphite powder were procured from Nice Chemicals, India. Monosodium dihydrogen phosphate, disodium hydrogen phosphate, and potassium ferrocyanide trihydrate were taken from Himedia, India. All the chemicals were of analytical reagent grade and used without additional purification at a laboratory temperature of $298 \mathrm{~K}$.

\subsection{Preparation of Electrodes}

BGPE was prepared by mixing graphite powder, and silicone oil in the ratio of 70:30 (w/w \%) in an agate mortar until the uniform paste was attained. The paste of graphite and silicone oil obtained was packed on a Teflon tube having $3 \mathrm{~mm}$ cavity and the surface was softened by polishing on a fresh tissue paper, and the electrical connection was made through a copper wire connected to the graphite paste. PNNMGPE was equipped by the electro-polymerization of $1.0 \mathrm{mM} \mathrm{NN}$ on the fresh surface of GPE.

\section{RESULTS AND DISCUSSIONS}

\subsection{Active Surface Area}

The active surface area of modified and bare electrodes was analyzed by $\mathrm{CV}$ method using $1.0 \mathrm{mM} \mathrm{K}_{4}\left[\mathrm{Fe}(\mathrm{CN})_{6}\right]$ in 0.1 $\mathrm{M} \mathrm{KCl}$ solution as a supporting electrolyte at $0.1 \mathrm{~V} / \mathrm{s}$ scan rate. Fig. (1) presents cyclic voltammograms (CVs) of $1.0 \mathrm{mM}$ $\mathrm{K}_{4}\left[\mathrm{Fe}(\mathrm{CN})_{6}\right]$ at BGPE (curve a) and PNNMGPE (curve b), here bare electrode depicts a lower peak current of $13.61 \mu \mathrm{A}$ at the peak potential of $0.332 \mathrm{~V}$ with a lower rate of electron migration than PNNMGPE (peak current of $32.07 \mu \mathrm{A}$ and peak potential of $0.215 \mathrm{~V}$ ). Therefore, the modified electrode demonstrates a faster rate of reaction, which mainly varies on the active surface area of the electrode and it is determined by the following Randles-Sevcik equation [58];

$$
\mathrm{I}_{\mathrm{p}}=2.69 \times 10^{5} \mathrm{n}^{3 / 2} \mathrm{~A} \mathrm{D}^{1 / 2} \mathrm{C} v^{1 / 2}
$$

Where ' $I_{p}$ '-peak current, ' $n$ '-number of electrons involved in the reaction, ' $D$ '-diffusion coefficient, 'A'-active surface area of the electrode, ' $v$ '-scan rate, and ' $\mathrm{C}$ '-concentration of $\mathrm{K}_{4}\left[\mathrm{Fe}(\mathrm{CN})_{6}\right]$. The obtained values of the active surface area for BGPE and PNNMGPE were $0.018 \mathrm{~cm}^{2}$ and $0.043 \mathrm{~cm}^{2}$, correspondingly. This result exposes that PNNMGPE promises a suitable platform for the electrochemical analysis of RF with the high sensitivity and fast rate of response.

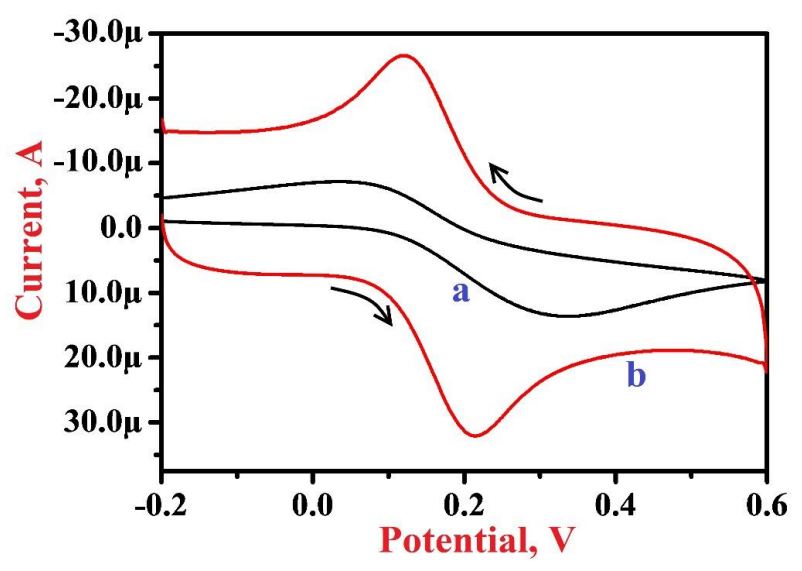

Fig. (1). $\mathrm{CVs}$ for $1.0 \mathrm{mM} \mathrm{K}_{4}\left[\mathrm{Fe}(\mathrm{CN})_{6}\right]$ on the surface of BGPE (curve a) and PNNMGPE (curve b) in $0.1 \mathrm{M} \mathrm{KCl}$ having the potential window of $-2.0 \mathrm{~V}$ to $0.6 \mathrm{~V}$, at the scan rate of $0.1 \mathrm{~V} / \mathrm{s}$.

\subsection{EIS Study}

EIS method is advantageous for analyzing the surface 
behaviors and conductivity of the bare and modified electrodes. Fig. (2) displays the Nyquist plots for PNNMGPE (curve a) and BCPE (curve b). Here, we observed a semi-circular part in both the plots of bare and unmodified electrodes, signifying the charge transfer phenomena and their diameter represents the charge transfer resistance (Rct). The 'curve a' and 'curve b' represent PNNMGPE and BCPE, with the subsequent Rct values being $90.96 \Omega$ and $355.00 \Omega$, correspondingly. Here, the modified PNNMGPE provides lesser Rct with high conductivity and faster electron transfer kinetics due to its modification effect [59].

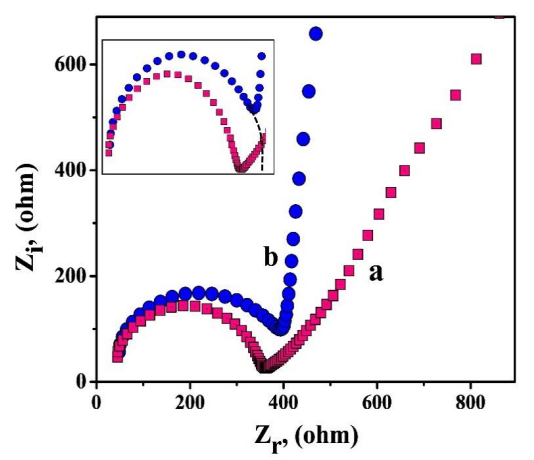

Fig. (2). Nyquist plots of of PNNMGPE (curve a) and BCPE (curve b).

\subsection{Electropolymerization of NN on BGPE}

Electropolymerization of NN in $0.2 \mathrm{M}$ PBS of $7.5 \mathrm{pH}$ on the surface of BGPE was done by cycling $10 \mathrm{CV}$ cycles with the potential range of $-1.0 \mathrm{~V}$ to $1.8 \mathrm{~V}$ at $0.1 \mathrm{~V} / \mathrm{s}$ scan rate. The enrichment of redox peak current of $\mathrm{NN}$ for each voltammetric probe was observed as shown in Fig. (3), which shows that the polymer layer is formed on the surface of the bare electrode. After the electrochemical polymerization, the modified electrode was rinsed with deionized water to eliminate the physically adsorbed materials.

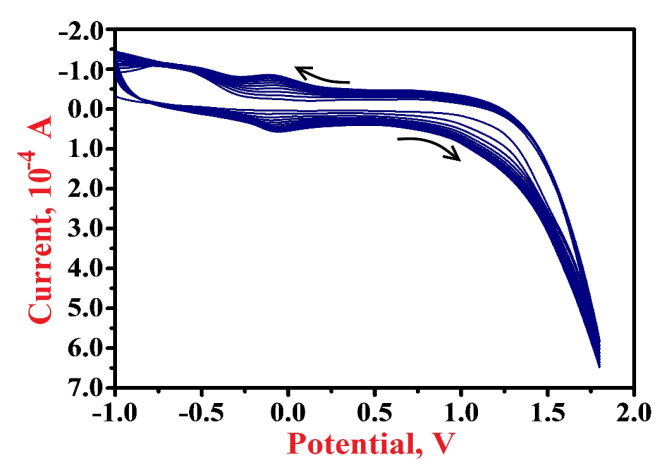

Fig. (3). CVs of electropolymerization of $1.0 \mathrm{mM} \mathrm{NN}$ in $0.2 \mathrm{M}$ PBS of $7.5 \mathrm{pH}$ on BGPE, at the potential window from $-1.0 \mathrm{~V}$ to $1.8 \mathrm{~V}$ at 0.1 $\mathrm{V} / \mathrm{s}$ scan rate.

\subsection{Influence of $\mathbf{p H}$}

The influence of solution $\mathrm{pH}$ on the electro-oxidation of
$0.1 \mathrm{mM} \mathrm{RF}$ at the surface of PNNMGPE was examined by varying solution $\mathrm{pH}$ in the range from 6.0 to 8.0 via LSV at the potential window from $0.6 \mathrm{~V}$ to $1.1 \mathrm{~V}$ at a scan rate of $0.1 \mathrm{~V} / \mathrm{s}$. Fig. (4A) discloses that with the increase of $\mathrm{pH}$, the oxidation potential of RF became more negative. It describes that the oxidation peak potential of RF on the surface of the modified electrode was declining with intensifying $\mathrm{pH}$ of the electrolyte with $0.0882 \mathrm{~V} / \mathrm{pH}$ slope value. Fig. (4B) reveals that the sensitivity of the PNNMGPE was low with lesser oxidation peak current response at the $\mathrm{pH}$ of 6.0, 6.5, 7.0 and 8.0, but at $7.5 \mathrm{pH}$, the sensitivity was very high with high oxidation peak current response. Therefore, $7.5 \mathrm{pH}$ was selected as an optimum $\mathrm{pH}$ for this analysis. The plot of oxidation potential against $\mathrm{pH}$ was plotted (Fig. 4C), which displayed a decent linear relation with the linear regression equation of $\mathrm{E}_{\mathrm{pa}}$ $(\mathrm{V})=0.209-0.0882 \quad(\mathrm{~V} / \mathrm{pH}) \quad\left(\mathrm{R}^{2}=0.9779\right)$, where $\mathrm{R}^{2}$ is the correlation coefficient.

\subsection{RF Electrochemical Reaction at BGPE and PNNMGPE}

Electrochemical action was deliberated for $0.1 \mathrm{mM} \mathrm{RF}$ in $0.2 \mathrm{M}$ PBS of pH 7.5 by CV and LSV approaches at BGPE and PNNMGPE under optimum experimental conditions. Fig. (5A) portrays the cyclic voltammograms $(\mathrm{CVs})$ in the presence of RF molecule in PBS of $7.5 \mathrm{pH}$ on the surface of BGPE (curve a) and PNNMGPE (curve b). Here, 'curve a' characterizes the electrochemical action of RF on an unmodified electrode surface, and discloses less sensitive redox peaks at the peak potential of $-0.466 \mathrm{~V}$ and $-0.517 \mathrm{~V}$, respectively. Also, 'curve b' denotes the electrochemical behavior of RF at PNNMGPE surface, which delivers more higher anodic and cathodic peaks with the high current response at $-0.451 \mathrm{~V}$ and $-0.583 \mathrm{~V}$ than BGPE. From the attained outcomes, the BGPE shows less electron transfer rate and low peak currents with lower catalytic activity. However, PNNMGPE displays a high electron transfer rate and enhanced peak currents with high catalytic action for RF redox nature. The enhancement of redox peak currents at the modified sensor is due to RF interaction with the PNNMGPE surface. RF molecule displays both oxidation and reduction peaks with a change in potential $(\Delta E \mathrm{E})$ of $0.132 \mathrm{~V}$, which specifies that the reaction mechanism of RF at PNNMGPE is quasi-reversible. These outcomes clearly clarify that the electrochemical nature of RF predominantly depends on the $\mathrm{pH}$ of PBS and PNNMGPE with adequate conductivity, fast electron transfer rate and suitable antifouling nature.

Fig. (5B) characterizes the linear sweep voltammograms (LSVs) of RF in PBS of $7.5 \mathrm{pH}$ at the scan rate of $0.1 \mathrm{~V} / \mathrm{s}$ on BGPE (curve a) and PNNMGPE (curve b) surfaces. Here 'curve a' indicates the RF oxidation at BGPE with a lower oxidation peak current of $-15.89 \mu \mathrm{A}$ at the oxidation peak potential $-0.468 \mathrm{~V}$. However, RF on the surface of PNNMGPE (curve b) shows improved oxidation peak current $(52.92 \mu \mathrm{A})$ at the oxidation peak potential of $-0.459 \mathrm{~V}$. This achieved information noticeably displays a satisfactory electrochemical action of RF at the modified sensor. 

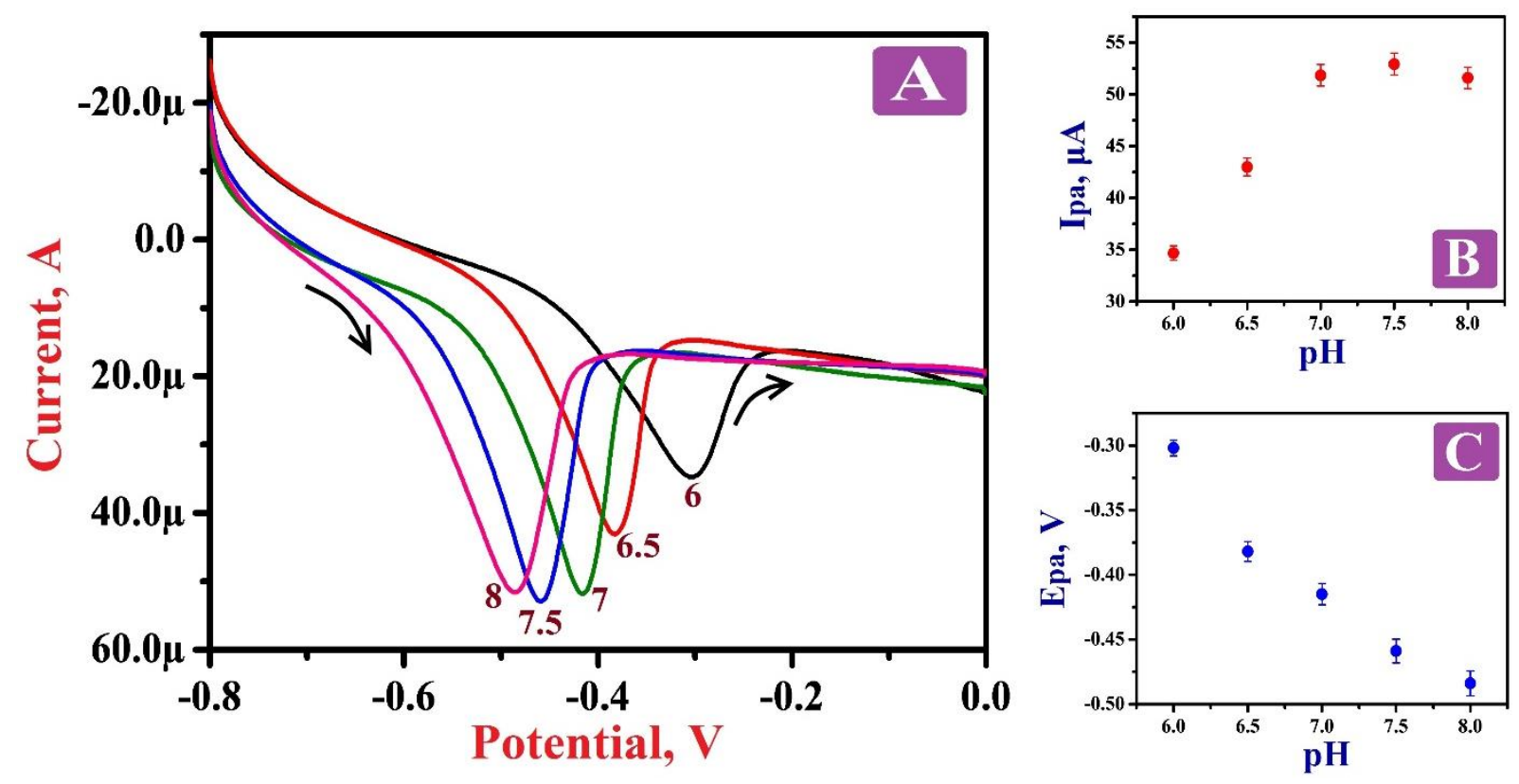

Fig. (4). (A) LSVs of $0.1 \mathrm{mM} \mathrm{RF}$ at PNNMGPE in $0.2 \mathrm{M}$ PBS of dissimilar $\mathrm{pH}$ in the range of 6.0 to 8.0 at $0.1 \mathrm{~V} / \mathrm{s}$ scan rate with the potential range of $-0.8 \mathrm{~V}$ to $0.0 \mathrm{~V}$. (B) The plot of oxidation peak potential v/s pH of PBS. (C) The plot of the oxidation peak current v/s pH of PBS.
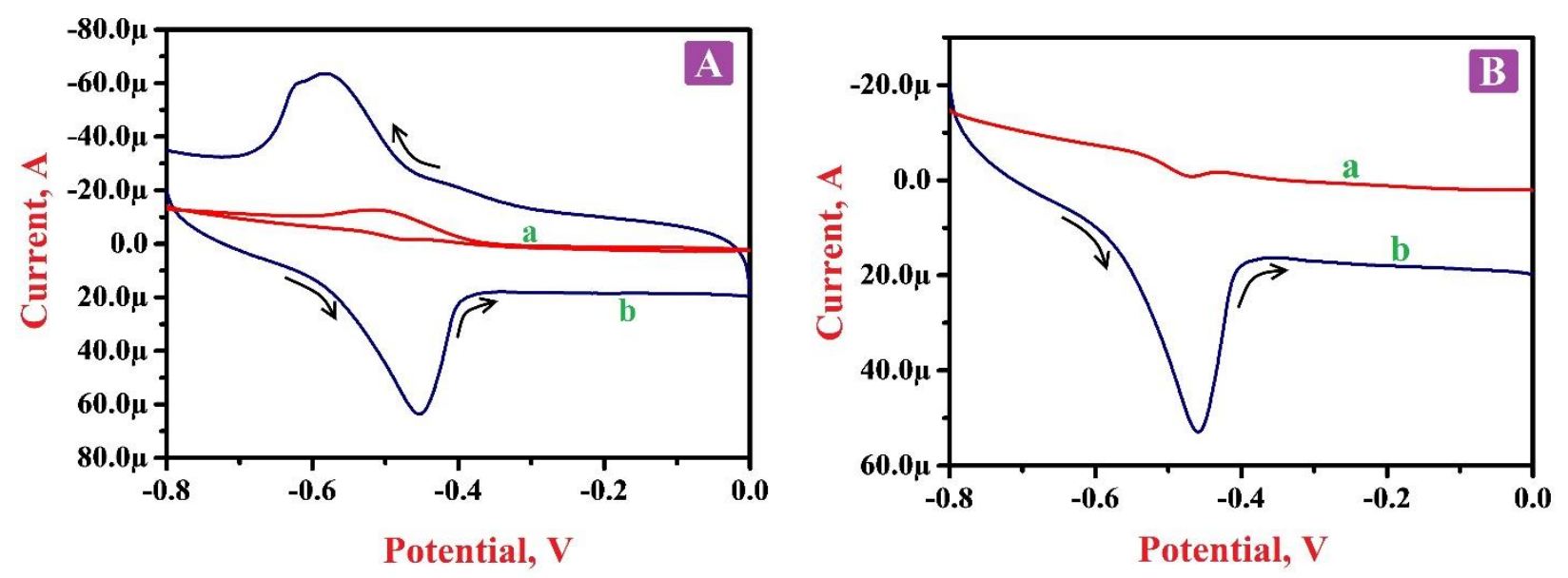

Fig. (5). (A) CVs of $0.1 \mathrm{mM} \mathrm{RF}$ in $7.5 \mathrm{pH}$ of PBS on BGPE (curve a) and PNNMGPE (curve b) with $0.1 \mathrm{~V} / \mathrm{s}$ scan rate. (B) LSVs of $0.1 \mathrm{mM}$ RF in $7.5 \mathrm{pH}$ of PBS on BGPE (curve a) and PNNMGPE (curve b) at $0.1 \mathrm{~V} / \mathrm{s}$ scan rate.

\subsection{Effect of Scan Rate}

The nature of the electrode reaction towards $0.1 \mathrm{mM} \mathrm{RF}$ in $0.2 \mathrm{M}$ PBS of $7.5 \mathrm{pH}$ was examined by operating $\mathrm{CV}$ by varying the scan rate between the range of $0.1-0.25 \mathrm{~V} / \mathrm{s}$. Fig. (6A) demonstrates the CVs of RF; here the oxidation peaks shifted to the positive value and the reduction peaks shifted to the negative side by the increase of scan rate. The graphs of oxidation peak current v/s scan rate (Fig. 6B) and logarithmic value of oxidation peak current $\mathrm{v} / \mathrm{s}$ logarithmic value of scan rate (Fig. 6C) shows fine linear associations with the linear regression equations $\mathrm{I}_{\mathrm{pa}}(\mu \mathrm{A})=14.76+503 v(\mathrm{~V} / \mathrm{s})\left(\mathrm{R}^{2}=\right.$ $0.9992)$ and $\log \mathrm{I}_{\mathrm{pa}}(\mu \mathrm{A})=2.63+0.83 \log v(\mathrm{~V} / \mathrm{s})\left(\mathrm{R}^{2}=\right.$ $0.9991)$, respectively. The results of these equations suggest that the redox reaction mechanism of RF on the surface of PNNMGPE takes place via adsorption controlled kinetics with the transfer of two electrons (Scheme 1).

\subsection{Simultaneous Analysis of RF with $A A$ and $D A$ at PNNMGPE and BGPE}

The simultaneous analysis of the projected PNNMGPE for $0.1 \mathrm{mM}$ RF was conducted in the presence of $1.0 \mathrm{mM} \mathrm{AA}$ and $0.1 \mathrm{mM}$ DA in PBS of $7.5 \mathrm{pH}$ by LSV method to assess the possible analytical effects. Fig. (7) displays LSVs for RF, AA and DA at BGPE (curve a) and PNNMGPE (curve b). Here 'curve b' shows clear and fine oxidation peaks for RF, AA and $\mathrm{DA}$ on PNNMGPE at the oxidation potential of $-0.469 \mathrm{~V}$, 
$-0.080 \mathrm{~V}$ and $0.138 \mathrm{~V}$, respectively. However, 'curve a' does not reveal clear peaks for RF, AA and DA. The results demonstrate good catalytic action of the modified electrode for the electro-oxidation of RF in the presence and absence of AA and DA.
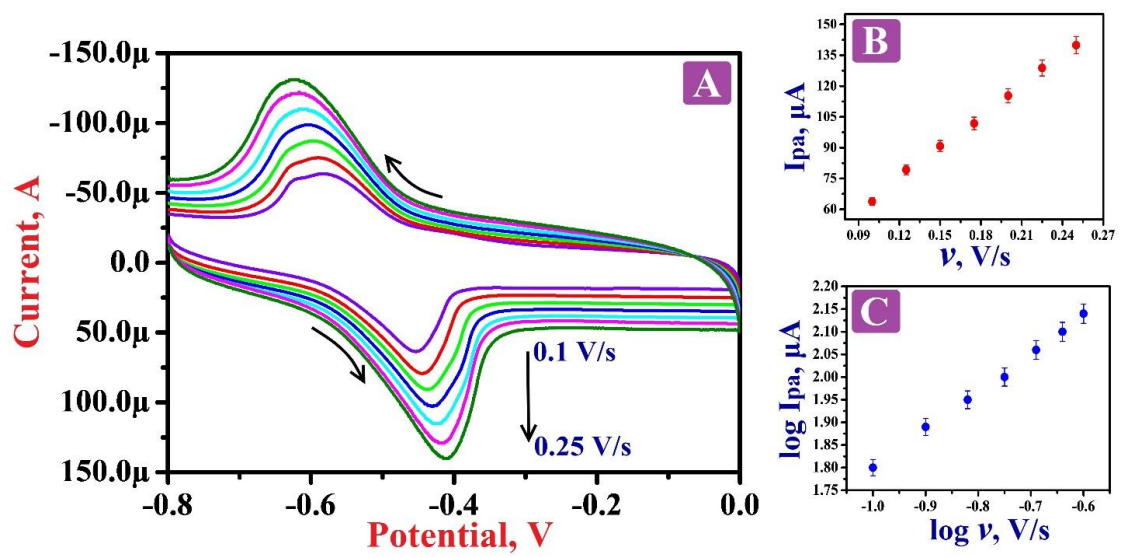

Fig. (6). (A) CVs of $0.1 \mathrm{mM} \mathrm{RF}$ in PBS $(7.5 \mathrm{pH})$ on PNNMGPE at different scan rates in the range of $0.1 \mathrm{~V} / \mathrm{s}$ to $0.25 \mathrm{~V} / \mathrm{s}$ with the potential window from $-0.8 \mathrm{~V}$ to $0.0 \mathrm{~V}$. (B) Plot of oxidation peak current against scan rate. (C) The plot of the logarithmic value of oxidation peak current $\mathrm{v} / \mathrm{s}$ logarithmic value of scan rate.

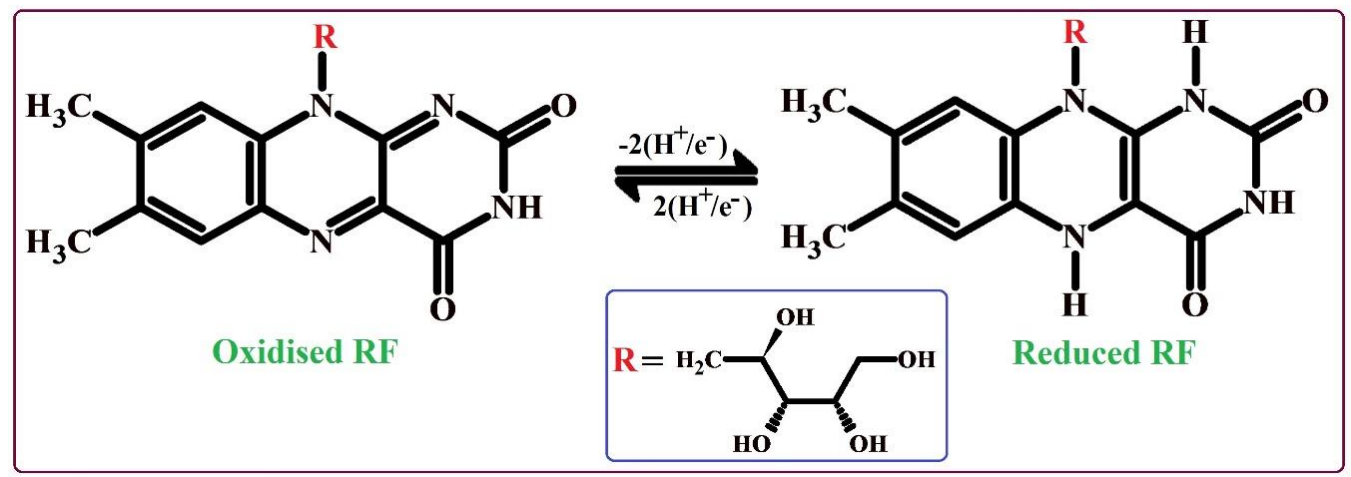

Scheme 1. The probable reaction mechanism of RF.

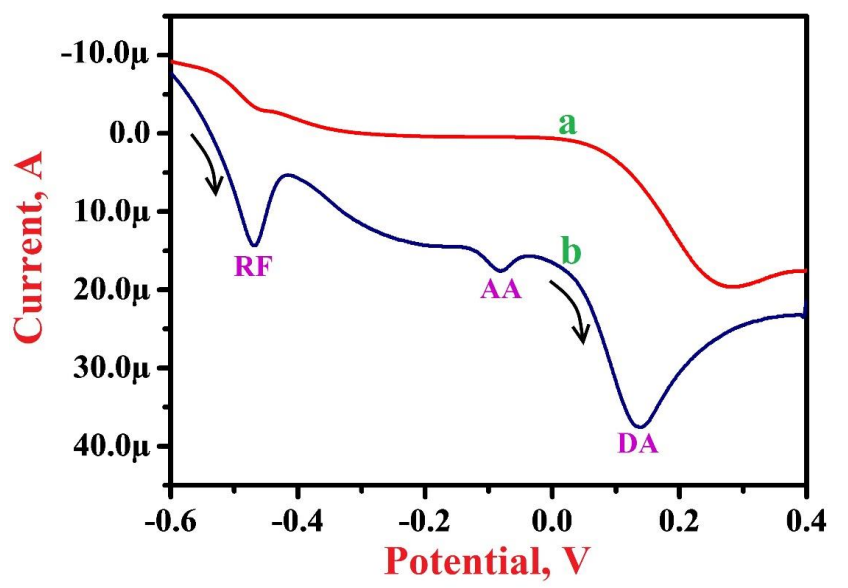

Fig. (7). LSVs of $0.1 \mathrm{mM}$ RF with $1.0 \mathrm{mM}$ AA and $0.1 \mathrm{mM}$ DA in $7.5 \mathrm{pH}$ of PBS on BGPE (curve a) and PNNMGPE (curve a), with the potential window from $-0.6 \mathrm{~V}$ to $0.4 \mathrm{~V}$, at $0.1 \mathrm{~V} / \mathrm{s}$ scan rate. 


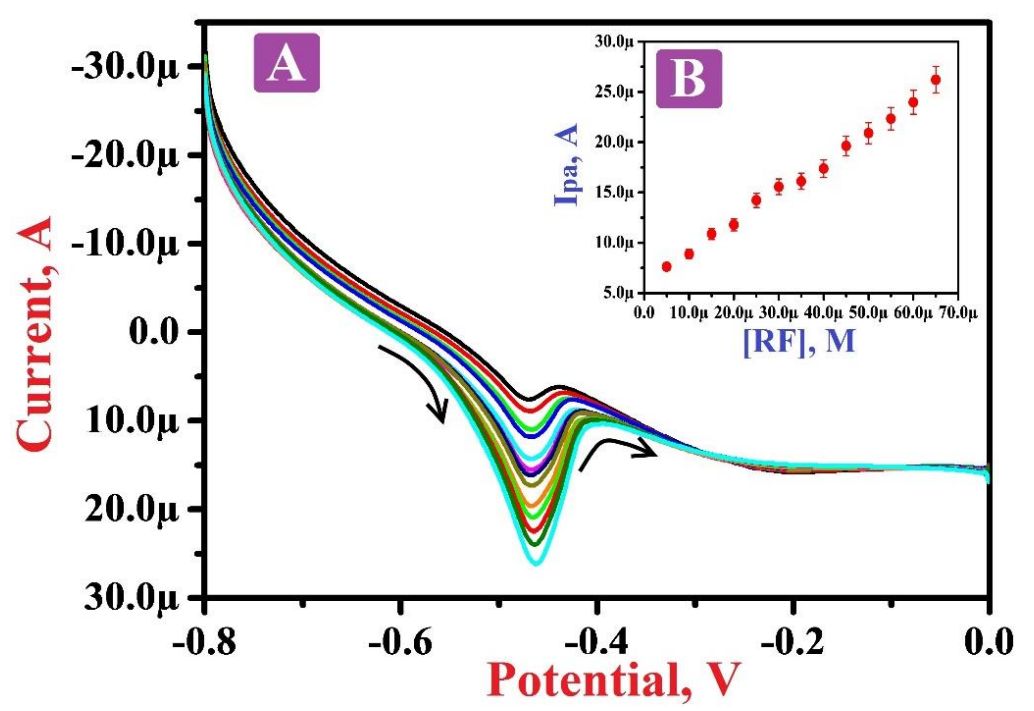

Fig. (8). (A) LSVs of different concentration RF $(5.0 \mu \mathrm{M}$ to $65.0 \mu \mathrm{M})$ at PNNMGPE in $0.2 \mathrm{M}$ PBS of $7.5 \mathrm{pH}$. (B) The plot of the oxidation peak current of RF v/s concentration of RF.

Table 1. Comparison of previously reported methods and LODs of RF with the current work.

\begin{tabular}{|c|c|c|c|c|}
\hline Technique & Electrode & Linear range $[\mu \mathrm{M}]$ & LOD $[\mu \mathrm{M}]$ & Reference \\
\hline DPV & $\begin{array}{l}\text { Sodium lauryl sulphate modified carbonnanotube and pencil graphite composite paste } \\
\text { electrode }\end{array}$ & $0.2-0.8 \& 1-5$ & 0.0166 & {$[50]$} \\
\hline DPV & Poly dl-phenylalanine modified carbon paste sensor & $6.0-30.0$ & 0.092 & [59] \\
\hline SWASV [1] & Bismuth film electrode & $1.0-9.0$ & 0.10 & {$[60]$} \\
\hline SWV [2] & Rotating disc glassy carbon Hematite $(\alpha$-Fe2O3) & $1.3-100$ & 8.40 & {$[61]$} \\
\hline $\mathrm{DPV}$ & $\mathrm{Bi} /$ annular band electrode & $10-337$ & 2.40 & {$[62]$} \\
\hline $\mathrm{CV}$ & Poly helianthin dye modified carbon paste electrode & $60-150$ & 0.0402 & [63] \\
\hline HPLC [3] & - & $20-90$ & 0.295 & {$[64]$} \\
\hline LSV & Poly Niacin modified carbon paste sensor & $5.0-65.0$ & 0.782 & Current work \\
\hline
\end{tabular}

\subsection{Concentration Variation}

Fig. (8A) depicts the LSVs of different RF concentrations in the range of $5.0 \mu \mathrm{M}$ to $65.0 \mu \mathrm{M}$ in PBS of $7.5 \mathrm{pH}$. The plot Fig. (8B) of the oxidation peak current of RF and the concentration of RF shows a good linearity with the regression equation of $\mathrm{I}_{\mathrm{pa}}(\mathrm{A})=6.0792 \times 10^{-6}+0.2999[\mathrm{RF}](\mathrm{A} / \mathrm{M})\left(\mathrm{R}^{2}=\right.$ 0.9974). Also, it displays that as the concentration of $\mathrm{RF}$ increases, the oxidation current of RF also increases. The values of LOD and LOQ were calculated to be $0.782 \mu \mathrm{M}$ and $2.7608 \mu \mathrm{M}$, respectively. Table $\mathbf{1}$ shows the comparison of some of the previous reports with our projected electrode and LOD $[49,59-63]$.

\subsection{Stability and Reproducibility of PNNMGPE}

The stability of the projected PNNMGPE for the detection of $\mathrm{RF}$ in $0.2 \mathrm{M}$ PBS ( $\mathrm{pH} 7.5$ ) was examined by $\mathrm{CV}$ by 30 subsequent $\mathrm{CV}$ cycles in optimal circumstances. The percentage of degradation value discloses that PNNMGPE exhibits $88 \%$ of the preliminary current signal even after 30 $\mathrm{CV}$ cycles, showing acceptable stability. The reproducibility of the PNNMGPE was analysed by cycling 5 consecutive CV cycles with $2.8 \%$ of relative standard deviation, showing excellent reproducibility.

\subsection{Analysis of RF in the Pharmaceutical Sample}

Determination of RF in a pharmaceutical sample (BComplex capsule) was completed by the application of the suggested PNNMGPE via the LSV technique. The resultant Bcomplex capsule sample was examined by the standard addition process. The suggested working electrode reveals a fine electrocatalytic action with superior sensitivity and consistency for the RF detection in the B-Complex capsule in the presence of some other molecules with an acceptable recovery (Table $\mathbf{2}$ ).

Table 2. Recovery of RF in B-Complex capsule.

\begin{tabular}{|c|c|c|c|}
\hline $\begin{array}{c}\text { Pharmaceutical } \\
\text { Sample }\end{array}$ & $\begin{array}{c}\text { Added } \\
\text { Concentration } \\
(\boldsymbol{\mu M})\end{array}$ & $\begin{array}{c}\text { Found } \\
\text { Concentration } \\
(\boldsymbol{\mu M})\end{array}$ & $\begin{array}{c}\text { Recovery } \\
(\mathbf{\%})\end{array}$ \\
\hline \multirow{2}{*}{$\begin{array}{c}\text { B-Complex } \\
\text { capsule }\end{array}$} & 5.0 & 5.17 & 103.4 \\
\cline { 2 - 4 } & 10.0 & 9.66 & 96.62 \\
\cline { 2 - 4 } & 20.0 & 18.84 & 94.22 \\
\hline
\end{tabular}

\section{CONCLUSION}

This work describes the high sensitive analysis of RF by the application of poly $(\mathrm{NN})$ modification on the surface of graphite paste. The electrochemical redox response of RF on 
the surface of the projected electrode was quasi-reversible with adsorption controlled kinetics. The comparative study displays that the BGPE was less sensitive than the modified sensor. The projected operating electrode shows an easy preparation process with low-cost, fine sensitivity and rapid response. The proposed PNNMGPE was effectively tested for the analysis of RF moiety in the B-Complex capsule sample as an analytical utility.

\section{CONSENT FOR PUBLICATION}

Not applicable.

\section{AVAILABILITY OF DATA AND MATERIALS}

Not applicable.

\section{FUNDING}

The study is financially supported by VGST, Bangalore, India under Research Project. No. KSTePS/VGST-KFIST (L1)2016-2017/GRD-559/2017-18/126 /333, 21/11/2017.

\section{CONFLICT OF INTEREST}

The authors declare no conflict of interest, financial or otherwise.

\section{ACKNOWLEDGEMENTS}

We gratefully acknowledge the financial support from the VGST, Bangalore.

\section{REFERENCES}

[1] E. Silva, and A.M. Edwards, Flavins photochemistry and photobiology., The Royal Society of Chemistry: Cambridge, UK, 2006, pp. 1-11.

[2] N. Travica, K. Ried, A. Sali, A. Scholey, I. Hudson, and A. Pipingas, "Vitamin C status and cognitive function: A systematic review", Nutrients, vol. 9, no. 9, 2017.E960 [http://dx.doi.org/10.3390/nu9090960] [PMID: 28867798]

[3] M.D. Hoffman, T.R. Valentino, K.J. Stuempfle, and B.V. Hassid, "A placebo-controlled trial of riboflavin for enhancement of ultramarathon recovery", Sports Med. Open, vol. 3, no. 1, p. 14, 2017. [http://dx.doi.org/10.1186/s40798-017-0081-4] [PMID: 28349501]

[4] A. Safavi, N. Maleki, H. Ershadifar, and F. Tajabadi, "Development of a sensitive and selective Riboflavin sensor based on carbon ionic liquid electrode", Anal. Chim. Acta, vol. 674, no. 2, pp. 176-181, 2010. [http://dx.doi.org/10.1016/j.aca.2010.06.012] [PMID: 20678627]

[5] H.B. White III, and A.H. Merrill Jr, "Riboflavin-binding proteins", Annu. Rev. Nutr., vol. 8, pp. 279-299, 1988.

[http://dx.doi.org/10.1146/annurev.nu.08.070188.001431] [PMID: 3060168]

[6] S. Sahreen, M.R. Khan, and R.A. Khan, "Evaluation of antioxidant activities of various solvent extracts of Carissa opaca fruits", Food Chem., vol. 122, pp. 1205-1211, 2010.

[http://dx.doi.org/10.1016/j.foodchem.2010.03.120] [PMID: 29086845]

[7] W.H. Sebrell, and R.E. Butler, "Riboflavin Deficiency in Man (Ariboflavinosis)", Public Health Rep., vol. 54, pp. 2121-2131, 1939. [http://dx.doi.org/10.2307/4583104]

[8] S. Selvarajan, A. Suganthi, and M.A. Rajarajan, "A facile synthesis of $\mathrm{ZnO} /$ Manganese hexacyanoferrate nanocomposite modified electrode for the electrocatalytic sensing of riboflavin", J. Phys. Chem. Solids, vol. 121 , pp. $350-359,2018$. [http://dx.doi.org/10.1016/j.jpcs.2018.06.005]

[9] M. Lane, and C.P. Alfrey Jr, "The anemia of human riboflavin deficiency", Blood, vol. 25, pp. 432-442, 1965. [http://dx.doi.org/10.1182/blood.V25.4.432.432] [PMID: 14284333]

[10] R.P. Webster, M.D. Gawde, and R.K. Bhattacharya, "Modulation of carcinogen-induced DNA damage and repair enzyme activity by dietary riboflavin", Cancer Lett., vol. 98, no. 2, pp. 129-135, 1996. [http://dx.doi.org/10.1016/S0304-3835(06)80022-4] [PMID: 8556699]

[11] I. Hassan, S. Chibber, A.A. Khan, and I. Naseem, "Riboflavin ameliorates cisplatin induced toxicities under photoillumination", PLoS One, vol. 7, no. 5, 2012.e36273

[http://dx.doi.org/10.1371/journal.pone.0036273] [PMID: 22567145]

[12] B.J. Petteys, and E.L. Frank, "Rapid determination of vitamin B2 (riboflavin) in plasma by HPLC", Clin. Chim. Acta, vol. 412, no. 1-2, pp. 38-43, 2011.

[http://dx.doi.org/10.1016/j.cca.2010.08.037] [PMID: 20816949]

[13] H. Qi, Z. Cao, and L. Hou, "Electrogenerated chemiluminesence method for the determination of riboflavin at an ionic liquid modified gold electrode", Spectrochim. Acta A Mol. Biomol. Spectrosc., vol. 78, no. 1, pp. 211-215, 2011.

[http://dx.doi.org/10.1016/j.saa.2010.09.023] [PMID: 21030300]

[14] R. Bartzatt, and T. Wol, "Detection and assay of vitamin B-2 (Riboflavin) in alkaline borate buffer with UV/Visible spectrophotometry", Int. Sch. Res. Notices, vol. 2014, 2014.453085 [http://dx.doi.org/10.1155/2014/453085] [PMID: 27379273]

[15] D. Hampel, E.R. York, and L.H. Allen, "Ultra-performance liquid chromatography tandem mass-spectrometry (UPLC-MS/MS) for the rapid, simultaneous analysis of thiamin, riboflavin, flavin adenine dinucleotide, nicotinamide and pyridoxal in human milk", $J$. Chromatogr. B Analyt. Technol. Biomed. Life Sci., vol. 903, pp. 7-13, 2012.

[http://dx.doi.org/10.1016/j.jchromb.2012.06.024] [PMID: 22819611]

[16] P.L. Lopez-de-Alba, L. Lopez-Martinez, V. Cerdab, and J. AmadorHernandezc, "Simultaneous determination and classification of riboflavin, thiamine, nicotinamide and pyridoxine in pharmaceutical formulations, by UV-Visible spectrophotometry and multivariate analysis", J. Braz. Chem. Soc., vol. 17, pp. 715-722, 2006.

[http://dx.doi.org/10.1590/S0103-50532006000400012]

[17] Y. Shen, P. Zhang, X. Kong, C. Guo, and J. Wang, "Simultaneous determination of water-soluble vitamins $\mathrm{C}, \mathrm{B} 1, \mathrm{~B} 2$ and B6 in almonds by high performance liquid chromatography", $S e P u$, vol. 23, no. 5, pp. 538-541, 2005. [PMID: 16350802]

[18] K. Li, "Simultaneous determination of nicotinamide, pyridoxine hydrochloride, thiamine mononitrate and riboflavin in multivitamin with minerals tablets by reversed-phase ion-pair high performance liquid chromatography", Biomed. Chromatogr., vol. 16, no. 8, pp. 504-507, 2002.

[http://dx.doi.org/10.1002/bmc.192] [PMID: 12474212]

[19] M. Franco, R. Jasionowska, and E. Salvatore, "Application of CZE method in routine analysis for determination of B-Complex vitamins in pharmaceutical and veterinary preparations", Int. J. Anal. Chem., vol. 2012, 2012.592650

[http://dx.doi.org/10.1155/2012/592650] [PMID: 22536244]

[20] S.S. Patil, and A.K. Srivastava, "Development and validation of a liquid chromatography method for the simultaneous determination of eight water-soluble vitamins in multivitamin formulations and human urine", J. AOAC Int., vol. 96, no. 6, pp. 1273-1280, 2013.

[http://dx.doi.org/10.5740/jaoacint.12-208] [PMID: 24645504]

[21] J.M. McMahon, "The analyses of six common vitamins by laser desorption mass spectroscopy", Anal. Biochem., vol. 147, no. 2, pp. $535-545,1985$.

[http://dx.doi.org/10.1016/0003-2697(85)90311-2] [PMID: 2990257]

[22] P. Viñas, N. Balsalobre, C. López-Erroz, and M. Hernández-Córdoba, "Liquid chromatographic analysis of riboflavin vitamers in foods using fluorescence detection", J. Agric. Food Chem., vol. 52, no. 7, pp. 1789-1794, 2004

[http://dx.doi.org/10.1021/jf030756s] [PMID: 15053510]

[23] I. Caelen, A. Kalman, and L. Wahlström, "Biosensor-based determination of riboflavin in milk samples", Anal. Chem., vol. 76, no. 1, pp. 137-143, 2004.

[http://dx.doi.org/10.1021/ac034876a] [PMID: 14697043]

[24] J.G.G. Manjunatha, "A novel poly (glycine) biosensor towards the detection of indigo carmine: A voltammetric study", Yao Wu Shi Pin Fen Xi, vol. 26, no. 1, pp. 292-299, 2018.

[http://dx.doi.org/10.1016/j.jfda.2017.05.002] [PMID: 29389566]

[25] N.P. Shetti, D.S. Nayaka, G.T. Kuchinad, and R.R. Naik, "Electrochemical behavior of thiosalicylic acid at $\gamma$-Fe2O3 nanoparticles and clay composite carbon electrode", Electrochim. Acta, vol. 269, pp. 204-211, 2018.

[http://dx.doi.org/10.1016/j.electacta.2018.02.170]

[26] M.M. Charithra, and J.G. Manjunatha, "Enhanced voltammetric detection of paracetamol by using carbon nanotube modified electrode 
as an electrochemical sensor", J. Electrochem. Sci. Eng., vol. 10, pp. 29-40, 2020.https://doi.org/https://doi.org/10.5599/jese.717

[http://dx.doi.org/10.5599/jese.717]

[27] J.G. Manjunatha, "A new electrochemical sensor based on modified carbon nanotube-graphite mixture paste electrode for voltammetric determination of resorcinol", Asian J. Pharm. Clin. Res., vol. 10, pp. 295-300, 2017.

[http://dx.doi.org/10.22159/ajpcr.2017.v10i12.21028]

[28] C Raril, and JG Manjunatha, "A simple approach for the electrochemical determination of vanillin at ionic surfactant modified graphene paste electrode", Microchem. J, vol. 154, 2020.

[http://dx.doi.org/10.1016/j.microc.2019.104575]

[29] C. Raril, and J.G. Manjunatha, Sensitive electrochemical analysis of resorcinol using polymer modified carbon paste electrode: A cyclic voltammetric studyAnal. Bioanal. Electrochem, vol. 10. 2018, pp. 488-98.

[30] C. Raril, and J.G. Manjunatha, "Electropolymerization of glycine at carbon paste electrode and its application for the determination of methyl orange", J. Sci. Islam. Repub. Iran, vol. 30, pp. 233-240, 2019.

[31] C. Raril, and J.G. Manjunatha, "Sensitive and selective analysis of nigrosine dye at polymer modified electrochemical sensor", Anal. Bioanal. Electrochem, vol. 10, pp. 372-382, 2018.

[32] JG Manjunatha, BE Kumara Swamy, GP Mamatha, C Raril, and L Nanjunda Swamy, Materials Today: Proceedings, vol. 5, pp. 22368-22375, 2018

[33] P.A. Pushpanjali, J.G. Manjunatha, and M.T. Shreenivas, "The electrochemical resolution of ciprofloxacin, riboflavin and estriol using anionic surfactant and polymer $\square$ Modified carbon paste electrode", ChemistrySelect, vol. 4, pp. 13427-13433, 2019. [http://dx.doi.org/10.1002/slct.201903897]

[34] J.G. Manjunatha, M. Deraman, N.H. Basri, N.S. Mohd Nor, I.A. Talib, and N. Ataollahi, "Sodium dodecyl sulfate modified carbon nanotubes paste electrode as a novel sensor for the simultaneous determination of dopamine, ascorbic acid, and uric acid", C. R. Chim., vol. 17, pp. 465-476, 2014.

[http://dx.doi.org/10.1016/j.crci.2013.09.016]

[35] J.G. Manjunatha, "Electroanalysis of estriol hormone using electrochemical sensor", Sens. Biosensing Res., vol. 16, pp. 79-84, 2017.

[http://dx.doi.org/10.1016/j.sbsr.2017.11.006]

[36] S. Edwin, "D' Souza, JG Manjunatha, C Raril, G Tigari and PA Pushpanjali, "Polymer modified carbon paste electrode as a sensitive sensor for the electrochemical determination of riboflavin and its application in pharmaceutical and biological samples", Anal. Bioanal. Chem. Res, vol. 7, pp. 461-472, 2020.

[37] N.S. Prinith, J.G. Manjunatha, and C. Raril, "Electrocatalytic analysis of dopamine, uric acid and ascorbic acid at poly (adenine) modified carbon nanotube paste electrode: A cyclic voltammetric study", Anal. Bioanal. Electrochem, vol. 11, pp. 742-756, 2019.

[38] MM Charithra, JG Manjunatha, and C Raril, "Surfactant modified carbon paste electrode as an electrochemical sensor for the enhanced voltammetric detection of estriol in the presence of dopamine and uric acid", Adv. Pharm. Bull, vol. 10, pp. 247-253, 2020.

[http://dx.doi.org/10.34172/apb.2020.029.]

[39] C. Raril, and J.G. Manjunatha, "Lingappa Nanjundaswamy, Siddaraju G, Ravishankar D K. Santosh Fattepur and Eshwarappa Niranjan, "Surfactant immobilized electrochemical sensor for the detection of indigotine", Anal. Bioanal. Electrochem, vol. 10, pp. 1479-1490, 2018.

[40] C. Raril, and J.G. Manjunatha, "Electrogenerated thin poly (threonine) film modified carbon nanotube paste electrode for the simultaneous resolution of dopamine and uric acid", Curr. Top. Electrochem., vol. 21, pp. 93-105, 2019

[41] B.M. Amrutha, J.G. Manjunatha, and S. Aarti, "Bhatt and PA Pushpanjali, "Fabrication of a sensitive and selective electrochemical sensing platform based on poly-L-leucine modified sensor for enhanced voltammetric determination of Riboflavin", J. Food Meas. Charact., vol. 14, 2020.

[http://dx.doi.org/10.1007/s11694-020-00608-9]

[42] C. Raril, J.G. Manjunatha, G. Tigari, and N. Hareesha, "Fabrication of the tartrazine voltammetric sensor based on surfactant modified carbon paste electrode", Open Access Journal of Chemistry, vol. 2, pp. 21-26, 2018.

[43] N Hareesha, and JG Manjunatha, "Surfactant and polymer layered carbon composite electrochemical sensor for the analysis of estriol with ciprofloxacin", Mater. Res. Innov, vol. 24, pp. 349-362, 2019. [http://dx.doi.org/10.1080/14328917.2019.1684657]

[44] G. Tigari, J.G. Manjunatha, C. Raril, and N. Hareesha, "Determination of riboflavin at carbon nanotube paste electrodes modified with an anionic surfactant", ChemistrySelect, vol. 4, pp. 2168-2173, 2019. [http://dx.doi.org/10.1002/slct.201803191]

[45] B.M. Amrutha, J.G. Manjunatha, S. Aarti Bhatt, and N. Hareesha, "Electrochemical analysis of evans blue by surfactant modified carbon nanotube paste electrode", J. Mater. Environ. Sci., vol. 10, pp. 668-676, 2019.

[46] C. Raril, and J.G. Manjunatha, "Fabrication of novel polymermodified graphene-based electrochemical sensor for the determination of mercury and lead ions in water and biological samples", J. Anal. Sci. Technol., vol. 11, 2020.

[http://dx.doi.org/10.1186/s40543-019-0194-0]

[47] N.S. Prinith, and J.G. Manjunatha, "Polymethionine modified carbon nanotube sensor for sensitive and selective determination of Ltryptophan", J. Electrochem. Sci. Eng., vol. 10, pp. 305-315, 2020. [http://dx.doi.org/10.5599/jese.774]

[48] J.G. Manjunatha, "A surfactant enhanced graphene paste electrode as an effective electrochemical sensor for the sensitive and simultaneous determination of catechol and resorcinol", Chem. Data Coll., vol. 25, 2020 .

[http://dx.doi.org/10.1016/j.cdc.2019.100331]

[49] N Hareesha, and JG Manjunatha, "Fast and enhanced electrochemical sensing of dopamine at cost-effective poly(DL-phenylalanine) based graphite electrode", J. Electroanal. Chem, p. 114533, 2020. [http://dx.doi.org/10.1016/j.jelechem.2020.114533]

[50] G Tigari, and JG Manjunatha, "A surfactant enhanced novel pencil graphite and carbon nanotube composite paste material as an effective electrochemical sensor for determination of riboflavin", J. Sci.: Adv. Mat. Dev, vol. 5, pp. 56-64, 2019.

[http://dx.doi.org/10.1016/j.jsamd.2019.11.001]

[51] P.A. Pushpanjali, and J.G. Manjunatha, "A sensitive novel approach towards the detection of 8-hydroxyquinoline at anionic surfactant modified carbon nanotube based biosensor: A voltammetric study", Phy. Chem. Res, vol. 7, pp. 813-822, 2019.

[http://dx.doi.org/10.22036/PCR.2019.198397.1663]

[52] N.S. Prinith, and J.G. Manjunatha, "Surfactant modified electrochemical sensor for determination of anthrone-A cyclic voltammetry", Mat. Sci. Ene. Technol, vol. 2, pp. 408-416, 2019. [http://dx.doi.org/10.1016/j.mset.2019.05.004]

[53] P.A. Pushpanjali, and J.G. Manjunatha, "Development of polymer modified electrochemical sensor for the determination of alizarin carmine in the presence of tartrazine", Electroanalysis, 2020. [http://dx.doi.org/10.1002/elan.202060181]

[54] P.A. Pushpanjali, J.G. Manjunatha, B.M. Amrutha, and N. Hareesha, "Development of carbon nanotube-based polymer-modified electrochemical sensor for the voltammetric study of Curcumin", Mater. Res. Innov., 2020.

[http://dx.doi.org/10.1080/14328917.2020.1842589]

[55] N. Hareesha, J.G.G. Manjunatha, C. Raril, and G. Tigari, "Design of novel surfactant modified carbon nanotube paste electrochemical sensor for the sensitive investigation of tyrosine as a pharmaceutical drug", Adv. Pharm. Bull., vol. 9, no. 1, pp. 132-137, 2019.

[http://dx.doi.org/10.15171/apb.2019.016] [PMID: 31011567]

[56] M.M. Charithra, and J.G. Manjunatha, "Poly (L-Proline) modified carbon paste electrode as the voltammetric sensor for the detection of estriol and its simultaneous determination with folic and ascorbic acid", Mat. Sci. Ene. Technol, vol. 2, pp. 365-371, 2019.

[http://dx.doi.org/10.1016/j.mset.2019.05.002]

[57] J.G. Manjunatha, "Electrochemical polymerised graphene paste electrode and application to catechol sensing", Open Chem. Eng. J., vol. 13, pp. 81-87, 2019.

[http://dx.doi.org/10.2174/1874123101913010081]

[58] N. Hareesha, J.G. Manjunatha, C. Raril, and G. Tigari, "Sensitive and selective electrochemical resolution of tyrosine with ascorbic acid through the development of electropolymerized alizarin sodium sulfonate modified carbon nanotube paste electrodes", Chemistry Select, vol. 4, pp. 4559-4567, 2019.

[http://dx.doi.org/10.1002/slct.201900794]

[59] N Hareesha, and JG Manjunatha, "A simple and low-cost poly (dlphenylalanine) modified carbon sensor for the improved electrochemical analysis of Riboflavin", J. Scie: Adva Mater and Devic, 2020.

[http://dx.doi.org/10.1016/j.jsamd.2020.08.005]

[60] ES Sa, PS da Silva, and CL Jost, Sens. Actuators B Chem., vol. 209, pp. 423-430, 2015.

[http://dx.doi.org/10.1016/j.snb.2014.11.136]

[61] L.C. Gribat, J.T. Babauta, H. Beyenal, and N.A. Wall, "New rotating 
disk hematite film electrode for riboflavin detection", J. Electroanal. Chem. (Lausanne Switz.), vol. 798, pp. 42-50, 2017.

[http://dx.doi.org/10.1016/j.jelechem.2017.05.008]

[62] K. Wegiel, and B. Bas, "Voltammetric characteristics and determination of riboflavin at the different metallic bulk annular band electrodes", J. Electrochem. Soc., vol. 165, pp. H393-H398, 2018. [http://dx.doi.org/10.1149/2.1201807jes]

[63] N. Hareesha, and J.G. Manjunatha, "Elevated and rapid voltammetric sensing of riboflavin at poly (helianthin dye) blended carbon paste electrode with heterogeneous rate constant elucidation", J. Iran. Chem. Soc, vol. 17, pp. 1507-1519, 2020.

[http://dx.doi.org/10.1007/s13738-020-01876-4]

[64] D.O. Riberio, D.C. Pinto, L.M.T.R. Lima, N.M. Volpato, L.M. Cabral, and V.P. Sousa, "Chemical stability of vitamins thiamine, riboflavin, pyridoxine and ascorbic acid in parentral nutrition for neonatal use", Nutr. J., vol. 10, pp. 1-47, 2011.

\section{C) 2020 Manjunatha et al.}

This is an open access article distributed under the terms of the Creative Commons Attribution 4.0 International Public License (CC-BY 4.0), a copy of which is available at: (https://creativecommons.org/licenses/by/4.0/legalcode). This license permits unrestricted use, distribution, and reproduction in any medium, provided the original author and source are credited. 